\title{
Analgesic Effect of Viddha, A Nonpharmacological, CostEffective Local Therapy of Ayurveda (An Indian System of Medicine) in Knee Osteoarthritis (OA): A Case Report
}

\author{
Vishakha Rajesh Wetal ${ }^{*}$, Arun Gupta \\ Department of Panchakarma, ChaudharyBrahmaprakash Ayurveda Charak Sansthan, New Delhi, India \\ Email address: \\ vishakhawetal@gmail.com (V.R.Wetal) \\ ${ }^{*}$ Corresponding author \\ To cite this article: \\ Vishakha Rajesh Wetal, Arun Gupta. Analgesic Effect of Viddha, A Nonpharmacological, CostEffective Local Therapy of Ayurveda (An \\ Indian System of Medicine) in Knee Osteoarthritis (OA): A Case Report. International Journal of Clinical and Experimental Medical \\ Sciences. Vol. 4, No. 3, 2018, pp. 35-38. doi: 10.11648/j.ijcems.20180403.12
}

Received: April 28, 2018; Accepted: May 31, 2018; Published: June 28, 2018

\begin{abstract}
Objective: Global statistics reveal over 100 million people worldwide suffer from OA, which is one of the most common causes of disability. According to the Arthritis Foundation, one in every two will develop symptoms of knee OA during their lives. One of the primary symptoms of persons with knee osteoarthritis is pain. The objective of this case report is to introduce Viddha, a non drug, local therapy from Ayurveda, an Indian System of Medicine as an intervention to achieve significant analgesia immediately, which is cost effective, has no side effects with possibility of arresting the progression of disease based on Ayurveda principle. Method and Result:-Viddhachikitsa(Viddha treatment)was done with the help of 26 gauge half inch short, fine, brown hypodermic needle.Its first sitting (done on $28^{\text {th }}$ Nov2017) provided immediate pain relief up to $60 \%$ in a female patient aged $47 \mathrm{yrs}$ with moderate Knee OA radiologically and severe symptomatically. In next two sittings (done on $30^{\text {th }}$ Nov and $4^{\text {th }}$ Dec 2017) there was $65 \%$ pain relief. Pain relief lasted till last follow up on $9^{\text {th }} \mathrm{Jan} 2018$. WOMAC index LK3.1on initial assessment before treatment was 88 which came down to 40 after treatment. Conclusion:-Viddha has therapeutic value in the treatment of Knee OA.
\end{abstract}

Keywords: Knee Osteoarthritis, Pain, Analgesic Effect, Viddha, Cost Effectiveness

\section{Introduction}

Global statistics reveal over 100 million people worldwide suffer from OA, which is one of the most common causes of disability. According to the Arthritis Foundation, one in every two will develop symptoms of knee OA during their lives [1]. The prevalence of symptomatic knee osteoarthritis has increased during the last 20 years, but the prevalence of radiographic knee osteoarthritis has not [1].

One of the primary symptoms of persons with knee osteoarthritis is pain. Severity of the joint pain can vary, from a minor ache to a severe and disabling pain accompanied by difficulty in walking due to instability of the knee. Pain worsens with certain activities, such as bending, kneeling, squatting, or stair climbing. Knee pain and stiffness that is worse after prolonged inactivity or rest, such as getting out of bed in the morning. [2] Due to the fact that OA is affecting millions worldwide and is often a progressive and irreversible degenerative process, functional improvement and pain control are reasonable treatment goals. [2] Also measures need to be developed to prevent early progression of the disease.

Currently the annually estimated cost per year to treat OA ranges from $\$ 15.5$ to $\$ 26.6$ billion, with some researchers estimating these figures to be much lower and the total cost is actually believed to exceed $\$ 89.1$ billion in the near future. Despite the available treatment methods, there still persist a host of inadequacies that make cost containment a real issue [3].

Viddhachikitsa, provides immediate pain relief. It is observed that Viddha practiced in patients with knee joint 
pain, not responding to NSAIDs and analgesics are getting immediate pain relief with increased range of motion. Moreover it is cost effective as there is requirement of very minimal resources for this treatment (26 gauge half inch short, fine, brown hypodermic needle). There are almost nil side effects with possibility of arresting the progression of disease based on Ayurveda principle.

Viddha is a non drug, local treatment form indicated for analgesia. It is described in 'SushrutSamhita', a basic and prime script of Ayurveda, an Indian system of medicine. It is used in various conditions for pain relief and specific sites of Viddha are described for every condition. [4]

There is guidance to carry out the Viddha at fleshy or hollow sites. It is directed that Vrihimukh, the instrument for Siravedh (type of bloodletting) should be inserted Yavamatra [5] (length of one type of rice). In case of knee joint, intra articular space is the hollow area and the 26 no half inch needle comes to be 'Yavamatra'. These principles when practiced in knee OA showed positive results in some patients.

\section{Case Report}

History of present illness:-A 47yrs female patient accompanied by her husband came to ChaudharyBrahmaprakash Ayurveda CharakSansthan Hospital, KheraDabar, New Delhi on 28/ 11/2017 with c/o severe right knee joint pain and swelling from last one and half years. Initially she was c/o parasthesia in arms and legs and all joint pain when consulted to the physician in Feb 2016. NCS all four limbs, Sr Calcium, TFT, KFT, LFT Lipid profile VitB12, D3 were WNL. RA factor and CRP were negative.After three months of medications there was mild improvement in parasthesia but this time she developed low backache, neck pain and right knee joint pain and swelling. She was not able to walk without support due to severe pain. There was limping gait. WOMAC index LK 3.1 for pain stiffness and physical function was $88 / 96$. Though $\mathrm{X}$-ray findings are suggestive of moderate OA, symptomatically it was severe. She was prescribed with internal Ayurvedic medications initially. Response to internal medications was minimal.

History of past illness:- IC bleed- 2011 details not available, K/C/O HTN.

Rx taken-Tab Amitop10mg 1HS, Tab Bravia20mg 1BD,(11/09/2013 to 23/102013) Tab Amitop 10mg 1/2HS, TabAidave G 1BD, Cap Hizide M 1OD (23/10/2013 to14/01/2013)Dulane30mg 1HS, Tab Aidave G 1OD, Cap Hizide M 1OD (15 ${ }^{\text {th }}$ Jan2014 to $5^{\text {th }}$ March 2014) Tab Gabapin NT 1/2HS, Tab Aidave G 1OD, Cap Hizide M 1OD ( $6^{\text {th }}$ March2014 to $10^{\text {th }}$ Oct2014)Tab Gabapin NT $1 / 2 \mathrm{HS}$, Tab Aidave G 1OD, Cap Hizide M 1OD Tab Clontril0.25mg SOS, Tab VoveranSR75mg SOS (1 $11^{\text {th }}$ Oct 2014 to) Tab Pregabid NT 1HS, Tab CalpepGoid 1OD, Cap Hizide M 1OD for 2 months,InjArachitol $600000 \mathrm{Iu} / \mathrm{IM} /$ once month for 3 months (Feb 2016 to April 2016)Tab Olmesar20mg 1OD, Cap Duloren30mg 1HS, Tab Esmopil40mg 1BD, Tab
Calpep Gold 1OD (for three months from 10/01/2017)

Investigations:-X-ray both knees showing degenerative changes suggestive of OA.

$\mathrm{O} / \mathrm{E}$ Crepitus ++, tenderness ++ , redness--, swelling ++ , ROM- Flexion-90degree, extension- 10degree

Pulse- $84 / \mathrm{min}$, BP- $140 / 80 \mathrm{~mm}$ of $\mathrm{Hg}, \mathrm{R} / \mathrm{R}-20 / \mathrm{min}$, Wt$85 \mathrm{~kg}$, RS- AEBE clear, CVS- S1S2 normal, CNS- conscious and oriented

\section{Management (Method)}

SOP of Viddha for Knee $O A$

1. Ask patient to lie down in supine position.

2. Flex the affected knee of the patient in 45 degree

3. Locate the lateral intra-articular space of that knee.

4. Clean it with spirit swab and insert the 26 gauge half inch short, fine, brown hypodermic needlegently perpendicularly to the whole length of it. One should not feel resistance while inserting the needle.

5. Keep it placed for 30 seconds and remove it gently

6 . Repeat the same procedure for medial articular space.

Table 1. Schedule of Viddha Followed and Results Obtained.

\begin{tabular}{llll}
\hline $\begin{array}{l}\text { No of } \\
\text { sitting }\end{array}$ & Date & $\begin{array}{l}\text { \% of pain relief (subjective, } \\
\text { immediately after Viddha) }\end{array}$ & $\begin{array}{l}\text { Duration } \\
\text { of pain } \\
\text { relief }\end{array}$ \\
\hline $1^{\text {st }}$ & $28 / 11 / 2017$ & $50 \%$ & \\
$2^{\text {nd }}$ & $30 / 11 / 2017$ & $50 \%$ & $6 \mathrm{wks}$ \\
$3^{\text {rd }}$ & $04 / 12 / 2017$ & $60 \%$ & \\
$4^{\text {th }}$ & $07 / 12 / 2017$ & $65 \%$ & \\
$5^{\text {th }}$ & $11 / 12 / 2017$ & $65 \%$ & \\
\hline
\end{tabular}

\subsection{Images- Viddha in Knee $O A$}

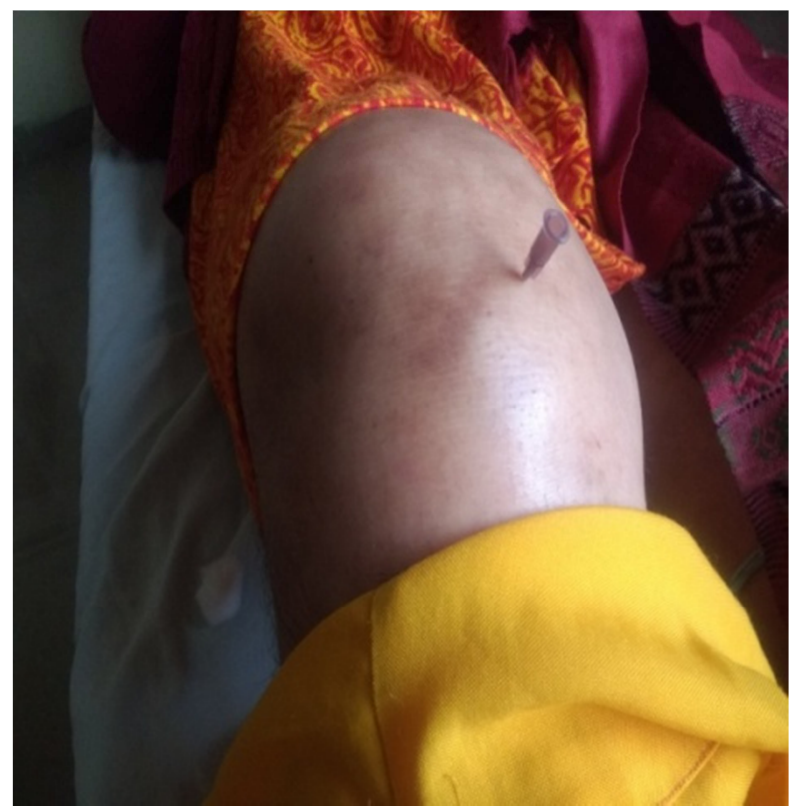

Figure 1. Viddha in medial articular space. 


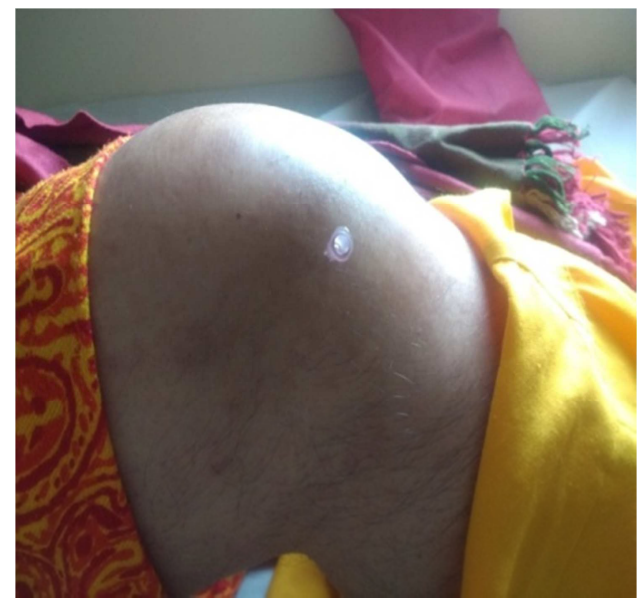

Figure2.Viddha in lateral articular space.

\section{Assessment Criteria: WOMAC3.1 (5-Point Likert) [6]}

Name: XYZ Central ID no (OPD no) - 109928 Date: $28 / 11 / 2017$

Instructions: Please rate the activities in each category according to the following scale of difficulty $0=$ None, $1=$ Slight, 2 = Moderate, 3 = Very, $4=$ Extremely

Table 2. WOMAC-Assessment before Viddha.

\begin{tabular}{|c|c|c|c|c|c|c|}
\hline \multicolumn{7}{|c|}{ one number for each activity is indicated by boldface and underline } \\
\hline \multirow[t]{5}{*}{ Pain } & 1. Walking & 0 & 1 & 2 & 3 & 4 \\
\hline & 2. Stair Climbing & 0 & 1 & 2 & 3 & 4 \\
\hline & 3. Nocturnal & 0 & 1 & 2 & 3 & 4 \\
\hline & 4. Rest & 0 & 1 & 2 & 3 & 4 \\
\hline & 5. Weight bearing & 0 & 1 & 2 & 3 & 4 \\
\hline \multirow[t]{2}{*}{ Stiffness } & 1. Morning stiffness & 0 & 1 & 2 & 3 & 4 \\
\hline & $\begin{array}{l}\text { 2. Stiffness occurring later } \\
\text { in the day }\end{array}$ & 0 & 1 & 2 & 3 & 4 \\
\hline \multirow{17}{*}{$\begin{array}{l}\text { Physical } \\
\text { Function }\end{array}$} & 1. Descending stairs & 0 & 1 & 2 & 3 & 4 \\
\hline & 2. Ascending stairs & 0 & 1 & 2 & 3 & 4 \\
\hline & 3. Rising from sitting & 0 & 1 & 2 & 3 & 4 \\
\hline & 4. Standing & 0 & 1 & 2 & 3 & 4 \\
\hline & 5. Bending to floor & 0 & 1 & 2 & 3 & 4 \\
\hline & 6. Walking on flat surface & 0 & 1 & 2 & 3 & 4 \\
\hline & 7. Getting in / out of car & 0 & 1 & 2 & 3 & 4 \\
\hline & 8. Going shopping & 0 & 1 & 2 & 3 & 4 \\
\hline & 9. Putting on socks & 0 & 1 & 2 & 3 & 4 \\
\hline & 10. Lying in bed & 0 & 1 & 2 & 3 & 4 \\
\hline & 11. Taking off socks & 0 & 1 & 2 & 3 & 4 \\
\hline & 12. Rising from bed & 0 & 1 & 2 & 3 & 4 \\
\hline & 13. Getting in/out of bath & 0 & 1 & 2 & 3 & 4 \\
\hline & 14. Sitting & 0 & 1 & 2 & 3 & 4 \\
\hline & 15. Getting on/off toilet & 0 & 1 & 2 & 3 & 4 \\
\hline & 16. Heavy domestic duties & 0 & 1 & 2 & 3 & 4 \\
\hline & 17. Light domestic duties & 0 & 1 & 2 & 3 & 4 \\
\hline
\end{tabular}

Total Score: $88 / 96=91.66 \%$
Table 3. WOMAC-Assessment after Viddha.

\begin{tabular}{|c|c|c|c|c|c|c|}
\hline \multicolumn{7}{|c|}{ one number for each activity is indicated in red color } \\
\hline \multirow[t]{5}{*}{ Pain } & 1. Walking & 0 & 1 & 2 & 3 & 4 \\
\hline & 2. Stair Climbing & 0 & 1 & 2 & 3 & 4 \\
\hline & 3. Nocturnal & 0 & 1 & 2 & 3 & 4 \\
\hline & 4. Rest & 0 & 1 & 2 & 3 & 4 \\
\hline & 5. Weight bearing & 0 & 1 & 2 & 3 & 4 \\
\hline \multirow[t]{2}{*}{ Stiffness } & 1. Morning stiffness & 0 & 1 & 2 & 3 & 4 \\
\hline & $\begin{array}{l}\text { 2. Stiffness occurring later } \\
\text { in the day }\end{array}$ & 0 & 1 & 2 & 3 & 4 \\
\hline \multirow[t]{17}{*}{$\begin{array}{l}\text { Physical } \\
\text { Function }\end{array}$} & 1. Descending stairs & 0 & 1 & 2 & 3 & 4 \\
\hline & 2. Ascending stairs & 0 & 1 & 2 & 3 & 4 \\
\hline & 3. Rising from sitting & 0 & 1 & 2 & 3 & 4 \\
\hline & 4. Standing & 0 & 1 & 2 & 3 & 4 \\
\hline & 5. Bending to floor & 0 & 1 & 2 & 3 & 4 \\
\hline & 6. Walking on flat surface & 0 & 1 & 2 & 3 & 4 \\
\hline & 7. Getting in / out of car & 0 & 1 & 2 & 3 & 4 \\
\hline & 8. Going shopping & 0 & 1 & 2 & 3 & 4 \\
\hline & 9. Putting on socks & 0 & 1 & 2 & 3 & 4 \\
\hline & 10. Lying in bed & 0 & 1 & 2 & 3 & 4 \\
\hline & 11. Taking off socks & 0 & 1 & 2 & 3 & 4 \\
\hline & 12. Rising from bed & 0 & 1 & 2 & 3 & 4 \\
\hline & 13. Getting in/out of bath & 0 & 1 & 2 & 3 & 4 \\
\hline & 14. Sitting & 0 & 1 & 2 & 3 & 4 \\
\hline & 15. Getting on/off toilet & 0 & 1 & 2 & 3 & 4 \\
\hline & 16. Heavy domestic duties & 0 & 1 & 2 & 3 & 4 \\
\hline & 17. Light domestic duties & 0 & 1 & 2 & 3 & 4 \\
\hline
\end{tabular}

Total Score:_40_/96=41.66_\%

\section{Discussion}

'Tridosha theory' forms the basis of Ayurvedic physiology, pathology and pharmacology. Though, the term 'Doșha' means 'the disturbing factor', it has got definite physiological importance in normal state. Basically three 'Doshas'- 'Vāta', 'Pitta' and 'Kapha' - are responsible for maintenance of homeostasis in the body, and health is nothing but a state of equilibrium of these 'Tridoshas'. Disease manifests as a result of disturbance in the state of equilibrium among these 'Doshas'[7]. 'Vāta' is responsible for all movements and it is the initiating and controlling factor. 'Pitta' performs the activities like digestion, metabolism, production of heat and that is why it is called 'Agni' meaning 'Fire'. 'Kapha' performs the functions like protection, strength, stability and resistance[7]. Pacification or expulsion of vitiated Doshas is basic principle for treatment of any disease condition.

There can be no pain without vitiation of Vata in the body [8]. In Knee OA there is lodging of vitiated Vata at Knee [9]. Properties of Vata like Ruksha(Dry), Laghu(light), Sheeta(cold), Vishad(unsticky),Khara(rough)[10] accounts for the wearing away of the cartilage. As the chronicity increases; the accumulated vitiated Vata progressively causes damage to the joint cartilage leadig to severity of the condition. After Viddha as the Vata is expelled out, the wearing away of the cartilage may be halted resulting in checking of progression of the condition. During Viddha in knee joint Vata along with indirect Rakta from VatavahiSira 
get released outside there by reducing the built up pressure by Vata resulting in immediate pain relief. There was maximum pain relief after first sitting of Viddha i.e. $50 \%$. In subsequent sittings some more pain relief was observed. Patient was satisfied with the treatment as her quality of life was improved significantly.

Osteoarthritis Research Society International (OARSI) published its first guidelines in 2008.The four groups of patients are identified in the new guidelines. One of the groups is, Patients with OA in one or both knees who have co-existing conditions such as diabetes, high blood pressure, cardiovascular disease, kidney failure, GI bleeding, depression or obesity [11]. This patient comes under this group. In patients with co-existing factors there is always greater risk for treatment with existing drug interventions. In chronic conditions patient does not respond to these interventions.Injecting corticosteroid compounds directly into affected joints can be useful for decreasing pain in the short term, although the effect tends to wear off after a few weeks. To maintain relief, you may need to have corticosteroid injections in the same joint every few months, or use another treatment. More than 3 to 4 injections per year have potential side effects.Hyaluronic acid injections seem to reach their peak benefit 8 weeks after the shot is given, and the effect lasts for about 24 weeks [11]. On the other hand Viddha provides immediate pain relief. It can be done as per required. There are no side effects as it is non drug intervention. Reducing needle size reduces pain and generally increases patient acceptance [12]. As needle used for this treatment is relatively thin and small in length, it is less painful. No one likes the needle prick but the fact is, once the patient gets significant pain relief immediately, he/she himself asks for the next prick as observed in this case.

\section{Conclusion}

There was maximum pain relief after first sitting of Viddha i.e.50\%. In subsequent sittings some more pain relief was observed. Unlike pharmacological interventions including corticosteroid injections, Viddha is safe; devoid of potential side effects. It is found as effective analgesic as conventional treatment options with possibility of arresting disease progression. Moreover it is significantly cost effective. If the similar results are observed in further systematic clinical studies on Viddha, it would help to lessen the treatment cost of the disease considerably.

\section{Conflict of Interest}

None.

\section{References}

[1] Nguyen UD, Zhang Y, Zhu Y, Niu J, Zhang B, Felson DT. Increasing Prevalence of Knee Pain and Symptomatic Knee Osteoarthritis: Survey and Cohort Data. Ann Intern Med. 2011;155:725-732. doi: 10.7326/0003-4819-155-11201112060-00004

[2] Garrett Hyman. What is Knee Osteoarthritis? Updated 06/14/2011 https://www.arthritishealth.com/types/osteoarthritis/what-knee-osteoarthritis.

[3] Bhatia D, Bejarano T, Novo M. Current interventions in the management of knee osteoarthritis. Journal of Pharmacy \&Bioallied Sciences. 2013;5(1):30-38. doi:10.4103/09757406.106561 .

[4] VaidyaJadavajiTrikamjiAcharya, editor, (edition reprint2012). SushrutSamhita of Sushrut, SharirSthana, SiravyadhvidhiShariram: Chapter8 Verse 17. Varanasi: Chukhambha Sanskrit Sansthan, 2012; 381.

[5] VaidyaJadavajiTrikamjiAcharya, editor, (edition reprint2012). SushrutSamhita of Sushrut, SharirSthana, SiravyadhvidhiShariram: Chapter8 Verse 9. Varanasi: Chukhambha Sanskrit Sansthan, 2012; 380.

[6] The Western Ontario and McMaster Universities Osteoarthritis Index(WOMAC)

https://static1.squarespace.com/static/55b581aee4b0b782bee2 9d82/t/55ff2b47e4b0fc002cb5ffc5/1442786119230/WOMAC. pdf +

[7] KishirPatwardhan. Concepts ofHuman Physiology in Ayurveda.Available from https://www.researchgate.net/publication/201915239_Concept s_of_HumanPhysiology_in_Ayurveda_Chapter

[8] VaidyaJadavajiTrikamjiAcharya, editor, (edition reprint2012). SushrutSamhita of Sushrut, Sutra Sthana, Aampakvishaniyam: Chapter 17 Verse 7. Varanasi:

ChukhambhaSurbhartiPrakashan, 2012; 83.

[9] VaidyaJadavajiTrikamjiAcharya, editor, (5 th ed.). CharakaSamhita of Agnivesh,Charaka, Dridhabala, Chikitsasthana, Vatavyadhichikitsita: Chapter28 Verse 37.Varanasi: Chukhambha Sanskrit Sansthan, 1997; 697.

[10] HariSadashivShastriParadkar, editor, (edition reprint2010). Ashtangahridaya of Vagbhata, Sutrasthana, Aayushkamiya: Chapter1 Verse11: ChaukhambhaSurabharatiPrakashan, 2010; 9.

[11] 25 Treatments for Hip and Knee Arthritis PainGuidelines recommend combining drugs with non-medicinal remedies. Available fromhttp://www.arthritis.org/living-witharthritis/pain-management/tips/25-treatments-for-hip-kneeoa.php

[12] Gill HS, Prausnitz MR. Does Needle Size Matter? Journal of diabetes science and technology (Online). 2007;1(5):725-729. 